Brit. F. industr. Med., 1968, 25, I19.

\title{
Dermatitis due to the Wood Dusts of Khaya anthotheca and Machaerium scleroxylon ${ }^{1}$
}

\author{
J. W. W. MORGAN, R. J. ORSLER, and D. S. WILKINSON \\ From the Forest Products Research Laboratory, Princes Risborough, Bucks., and Wycombe General Hospital, \\ High Wycombe, Bucks.
}

The causes of several cases of dermatitis at three furniture factories have been investigated. At two factories the trouble was traced to the wood of Khaya anthotheca, one of the species which comprise African mahogany. At the other factory the wood of Machaerium scleroxylon, a timber of similar appearance to Rio rosewood, was implicated. The relationship was established in each case by patch tests. Workers allergic to $K$. anthotheca reacted strongly to the constituent anthothecol whilst those allergic to $M$. scleroxylon were strongly sensitized by (R)-3, 4-dimethoxydalbergione and its related quinol.

The increased use, since the war, of exotic timbers for furniture manufacture has given rise to a number of problems due to the dust created during machining processes such as sanding and sawing. These manifest themselves as (I) irritation of the lungs, respiratory passages, and eyes, resulting in coughing, sneezing, streaming eyes, and nose bleeding; (2) skin reactions of primary irritant or sensitization type; and (3) general constitutional upset causing headache, nausea, giddiness or disturbance of vision.

The skin irritation has in several instances been shown to be due to the presence of specific extractable constituents and it is reasonable to assume that these are also the cause of the other symptoms.

In a thorough review of the literature Sandermann and Barghoorn (1956) described over 40 wood species which have been reported as giving rise to symptoms of illness. In only a few cases, however, had direct tests been carried out to correlate the symptoms with specific chemical constituents. In recent years Sandermann, Dietrichs, and Schulz (see Table I) have carried out further investigations and in several cases have established, by patch testing, a relationship between sensitizing activity and certain naturally occurring constituents of the wood dusts concerned.

${ }^{1}$ This work was reported at a combined meeting of the Sections of Dermatology and Occupational Medicine of the Royal Society of Medicine on April 21, 1966.

Received for publication October 10, 1967.
At the Forest Products Research Laboratory information concerning the harmful effects of timbers has been collected from enquiries which are sent in from time to time by timber users. From the number of reports received it is clear that certain timbers are more troublesome than others. Seven timbers most commonly reported to us as causing trouble during working are listed in Table II and each one can be considered as potentially irritating.

In addition to these there are a number of timbers for which only occasional reports are received and in consequence these are less well authenticated. In such cases it is wiser to reserve judgement on the potential toxic nature of the timber lest other factors have contributed to the effect, e.g., the inclusion of an irritant species of similar appearance in a batch of otherwise harmless timber. As far as the timbers causing respiratory irritation and those causing general malaise are concerned, confirmation must await the occurrence of further cases, but those dusts which cause irritation of the skin can be identified directly by means of patch tests where suitable test subjects are available. It has been our practice to follow up cases of the latter type which come to our notice and to identify the wood responsible, the nature of the toxicity (primary irritant or sensitization) and, when possible, the sensitizing constituents present.

Three outbreaks of dermatitis at local furniture factories have afforded the opportunity to carry out such investigations. The wood involved at two factories was Khaya anthotheca, which has been in 
TABLE I

Active Constitumnts Isolated fRom Some Sensitizing Woods

\begin{tabular}{l|l|l|}
\hline Wood & \\
\hline
\end{tabular}

\footnotetext{
${ }^{1}$ Authors cited described the allergen as a red quinone. The chemical structure of this constituent was later established by Marini Bettolo, Casinovi, and Galeffi (1965).

${ }^{2}$ The structure of these allergenic constituents was determined by Eyton, Ollis, Sutherland, Gottlieb, Magalhaes, and Jackman (1966b).
}

general use for many years, apparently without trouble, whilst at the other factory the wood concerned (Machaerium scleroxylon) was introduced as a substitute for Rio rosewood and is rarely encountered commercially in this country.

\section{Khaya anthotheca}

Khaya anthotheca is one of three Khaya species which comprise the major part of the timber known commercially as African mahogany. The timber is used extensively in the furniture trade and until 1964 there was little evidence that workers could be affected by the dust. The published account of the first outbreak (Morgan and Wilkinson, 1965a, b) clearly implicated $K$. anthotheca as the sole sensitizing species of the three, and its constituent anthothecol was shown to have a strong sensitizing action on the affected patients. These findings have now been largely confirmed as a result of the investigation of a further incident at another factory where at least five out of 55 employees at risk were affected by the dust. In addition, three other men complained of irritation but two of these had a skin condition of a different origin and did not react in the patch tests. The remaining man reacted to 
TABLE II

Woods Commonly Reported as Having an 'IrRItating' Dust

\begin{tabular}{ll|c|c}
\hline \multirow{2}{*}{ Wood } & \multicolumn{2}{|c|}{ Effect } \\
\cline { 2 - 4 } & & Respiratory & Skin \\
\hline Dahoma (Piptadenia africana) &. & $\star$ & \\
Guarea (Guarea spp.) &.. & $\star$ & $\star$ \\
Iroko (Chlorophora excelsa) &. & & $\star$ \\
Makoré (Mimusops heckelii) &. & $\star$ & \\
Mansonia (Mansonia altissima) &. & $\star$ & $\star$ \\
Western red cedar (Thuja plicata).. & $\star$ & $\star$ \\
White peroba (Paratecoma peroba) & & $\star$ \\
& & \\
\hline
\end{tabular}

^Effect established by the receipt of several independent enquiries.

$K$. ivorensis only, the first positive reaction we have encountered for this species; however, this patient had suffered from seborrhoeic dermatitis in the past and the relevance of this patch test is doubtful.

Patch tests were applied in the standard manner on the backs of the eight employees using Dalmas 984 waterproof test patches which were read at 48 and 96 hours. Samples of dust from three sites in the factory, authentic $K$. ivorensis and $K$. anthotheca dust, and $0.1 \%$ anthothecol were used. The results summarized in Table III show that five of the employees had become sensitized to $K$. anthotheca whilst one had a sensitivity to $K$. ivorensis. Chemical examination of the factory dusts $a, b$, and c agreed with these results in that dusts $a$ and $b$, which gave positive patch reactions, also gave a positive reaction in the test for $K$. anthotheca described by Morgan and Orsler (1967). The negative results obtained with $0.1 \%$ anthothecol for patients 3, 4, and 5 may indicate that the concentration was too low but this was chosen to avoid unnecessarily violent reactions.

The clinical features of the outbreak were similar to those of the earlier one. The rash was, generally, not severe and, although the eyelids were affected, in no case had these become markedly swollen. The sides of the neck were particularly affected and in two men the hairline and lobes of the ears. The forearms and other parts of the body were variably involved. The eruption cleared up rapidly with treatment or during a short period of sick leave but relapsed on the man's return to work. The working conditions in the factory were good.

In the period between the two outbreaks, $K$. anthotheca dust and anthothecol were added to routine patch tests in 20 patients including, specifically, wood workers referred to the dermatology clinic. With the exception of two men, who had also apparently contracted a (traced) Khaya sensitivity, none of these patients reacted.

The results obtained using the different samples of factory dusts clearly emphasize the need for caution in testing with materials of commercial origin. Samples a and b obviously contain $K$. anthotheca whereas sample $c$ does not. The same considerations apply to solid samples for it is impossible to distinguish visually between the timber from $K$. ivorensis and that from $K$. anthotheca. It is important, therefore, that patch tests be carried out using botanically authenticated materials, in addition to samples supplied from the area of work.

TABLE III

Results of Patch Tests with Khaya SpP. (I967 OUtbreak)

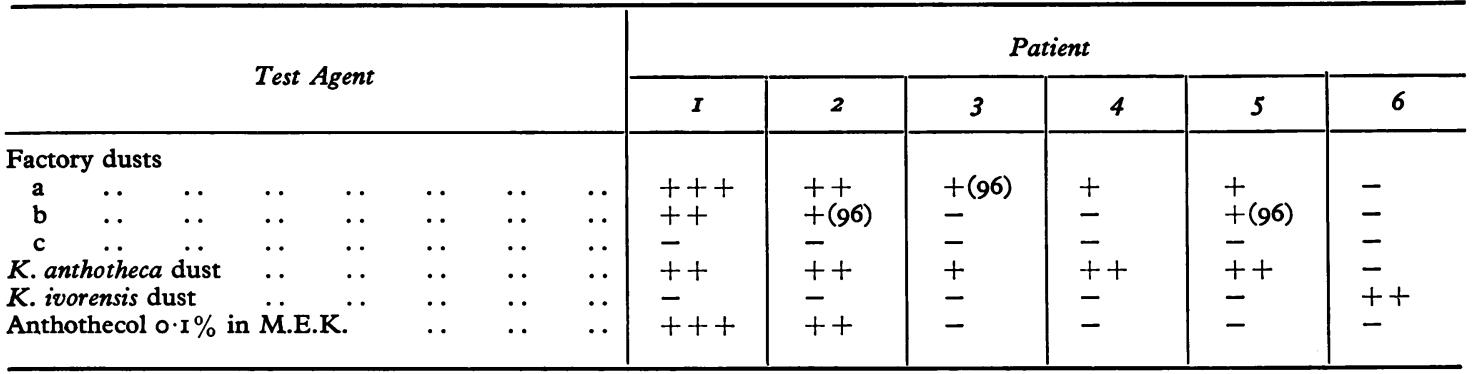

Two other patients who had a negative reaction to all extracts were tested.

+ erythema

++ erythema and oedema

+++ erythema, oedema, and vesicles

++++ intense vesicular or bulbous reaction

(96) visible only at 96 hours. 


\section{Machaerium scleroxylon}

History The investigation which led to the identification of this wood as a sensitizer was initiated when we were asked to investigate an outbreak of apparent dermatitis among employees of a factory concerned with the manufacture of special high-grade furniture. At the time of the trouble only two woods were being processed in the factory-teak (Tectona grandis) and Rio rosewood (Dalbergia nigra), and these had been in frequent use there for some years without trouble. However, rosewood from a new supplier had just been introduced and, although at the time this was thought to be genuine Rio rosewood, it was shown later to be a substitute-Machaerium scleroxylon.

The premises consisted of two shops, both fitted with adequate dust extraction equipment. This particular factory had been fairly free from dermatitis in the past, although there had been two cases of dermatitis due to Makoré in the previous year.

The first signs of dermatitis appeared very shortly after the new consignment of 'rosewood' had been received, two of the three workers delegated to unload the timber being affected within four days of handling it. In another worker, symptoms appeared a few days later, and three more men were affected after two weeks. Another employee was subsequently affected, making a total of seven cases within three weeks, out of a total of 24 men at risk. The eruption began with itching, quickly followed by an eczematous dermatitis involving the hands, cheeks, lips, forehead, neck, and the exposed areas generally. In some it spread to the upper arms and trunk in a diffuse patchy manner. All those affected, however, showed a consistent pattern involving the face and neck, with the rash stopping at the collar line; eyelid swelling was not pronounced. The rash increased rapidly in intensity and the men became anxious. The employers, pending the results of this investigation, very wisely stopped work on this consignment of wood and, temporarily, on the authentic Rio rosewood also. Thereafter the men's rashes subsided.

Identification of the Wood Examination of samples of the teak and Rio rosewood of established use in the factory confirmed that they were correctly named, their structures agreeing with those of $T$. grandis and D. nigra respectively. However, the rosewood obtained from the new supplier was definitely not $D$. nigra and its structure was in close agreement with that of $M$. scleroxylon (Phillips, 1966). Further support for this view came from thin layer chromatography of the petroleum extract of the wood on silica using chloroform as eluent. The pattern of the spots obtained under both visible and<smiles>[X]C1=C(O[CH])C(=O)C(C(C=C)(C=C)c2ccccc2)=CC1=O</smiles>

$$
\begin{array}{ll}
\text { I } & X=O M e \\
\mathrm{X} & =\mathrm{H}
\end{array}
$$<smiles>[X]c1cc2oc(=O)cc(-c3ccccc3)c2cc1OC</smiles>

III $X=O M e$ IV $\mathrm{X}=\mathrm{OH}$<smiles>C=CC(c1ccccc1)c1cc(O)c(OC)c(OC)c1O</smiles>

II<smiles>C=CC(c1ccccc1)c1cc(=O)c(OC)co1</smiles>

VI ultraviolet light closely resembled those similarly derived from an authentic sample of $M$. scleroxylon (from the Forest Products Research Laboratory collection) and were distinct from the chromatographic patterns from $D$. nigra (both factory and F.P.R.L. samples). An account of the extractives of $M$. scleroxylon has been published (Eyton, Ollis, Fineberg, Gottlieb, Guimaraes, and Magalhaes, 1966a) and four main components, (R)-3, 4-dimethoxydalbergione (I), the related quinol (II), methyldalbergin (III), and dalbergin (IV), described in that account were clearly discernible on the chromatographic plate. The leading orange spot had the same $R_{f}$ value as an authentic sample of (R)-3, 4-dimethoxydalbergione. A sample of the orange compound isolated from a preparative plate and further purified by vacuum distillation and crystallization at $0^{\circ}$ from light petroleum gave red crystals, m.p. $40-4 \mathrm{I}^{\circ}[\alpha]_{\mathrm{D}}+6 \mathrm{I}^{\circ}\left(\mathrm{c}, \mathrm{I}\right.$ in $\left.\mathrm{CHCl}_{3}\right)$, identical with (R)-3, 4-dimethoxydalbergione. The identity was confirmed by analysis, mixed melting point, and comparison of infrared and nuclear magnetic resonance spectra. The second visible spot was initially pale yellow but on standing this slowly became deep orange. If, when the colour change was complete, the spot was eluted and reapplied to a fresh plate the compound then behaved as the leading orange spot. Clearly this was the quinol corresponding to the quinone identified above, which becomes oxidized on the plate. The rapid oxidation of this compound did not allow its isolation in a pure state, but the infrared spectrum of a sample of the syrup obtained by preparative thin layer chromatography showed the presence of hydroxyl absorption as expected.

The two remaining compounds did not show up under visible light but under ultraviolet illumination they appeared as two greenish-blue spots between the leading yellow spots and the origin. These compounds were identified as dalbergin and methyldalbergin by cochromatography with authentic markers.

Patch Tests In the first of several series of patch tests, aimed at determining the responsible wood, seven 
workers were tested. They all reacted to teak dust but this is known to be an irritant when applied neat. True Rio rosewood (D. nigra) dust also produced a moderate positive reaction in all men, but the new consignment dust (M. scleroxylon) produced a very strong and persistent reaction in six out of seven and a mild one in the seventh man. When extracts of these wood dusts were applied as solutions in methyl ethyl ketone ( $1 \mathrm{~g}$. dust in IOO ml. M.E.K.) the teak reactions were uniformly negative; the $D$. nigra gave only one mild positive out of the seven tested, but the $M$. scleroxylon gave a positive reaction in all seven cases.

In subsequent weeks another man (not from the same factory) was found to have a wood dermatitis due to $M$. scleroxylon but the source in this case could not be traced. This patient was included in all subsequent patch tests, having shown similar initial results to those above, and a total of eight patients was thus investigated.

Further tests were then carried out using separated extracts of the wood of $M$. scleroxylon and the exhaustively extracted wood dust, but considered it was impracticable to test all patients with all extracts. Successive Soxhlet extraction of the sawdust with light petroleum, ether, acetone, and methanol for 24 hours each gave crude extracts as shown in Table IV. A portion of the petrol extract was then separated by preparative thin layer chromatography on silica plates in chloroform. The bands corresponding to 3,4-dimethoxydalbergione (I), the related quinol (II), methyldalbergin (III), and dalbergin (IV) described earlier were each removed from the plate by a scraper and also the mixture of substances (P-5) which remained at the origin. Each portion of silica powder was then leached with ether to afford the individual fractions, which were then evaporated. Solutions of I $(0.1 \%)$, II $(0.3 \%)$, III $(0.04 \%)$, IV $(0.03 \%)$, and P-5 $(0.03 \%)$ in M.E.K. were then prepared, the ratio of the strengths being approximately the ratio of their natural abundance in the wood. By solvent treatment and thin layer chromatography the ether extract was divided into four fractions, E-I, E-2, $\mathrm{E}-3$, and E-4, and the acetone extract into two fractions, A-I and A-2; in addition to these constituents, both extracts contained small amounts of I, II, III, and IV. These fractions (excluding I, II, III, and IV) and the methanol extract $M$ (which was not fractionated) were tested as $0.2 \%$ solutions in ethanol or M.E.K. Also the exhaustively extracted $M$. scleroxylon dust was applied in petroleum jelly.

The results of testing these fractions (Table IV) showed that compounds I and II were strongly active whereas fractions P-5, E-I, E-2, and A-I were inactive, as was the fully extracted wood dust. The intermediate activities of the remaining fractions E-3, E-4, and A-2 were reduced by chromatographing the fractions again to remove traces of constituents $I$ and II, and it seems probable that the skin-sensitizing action of the wood dust can be attributed entirely to these two related constituents.

Finally, reactions to the pure compounds (R)-3, 4-dimethoxydalbergione (I) (from $M$. scleroxylon), (R)-4-methoxydalbergione (V) (from $D$. nigra), and its enantiomer, (S)-4-methoxydalbergione (VI), were com-

TABLE IV

Results of Patch Tests with Extracts of M. scleroxylon

\begin{tabular}{|c|c|c|c|c|c|c|c|c|c|c|}
\hline & & & n So & & & & Crude Extract & Fractions & Patch Test & $\begin{array}{l}\text { Repeat after } \\
\text { Removal of }\end{array}$ \\
\hline Light petrc & oleum & . & $\cdots$ & . & . & .. & $\begin{array}{c}\text { Red syrup } \\
5.7\end{array}$ & $\begin{array}{l}\text { I quinone } \\
\text { II quinol } \\
\text { III } \\
\text { IV } \\
\text { P-5 }\end{array}$ & $\begin{array}{c}4 / 5 \\
4 / 4 \\
\text { I/4 slight } \\
\text { I/4 slight } \\
\text { o/4 }\end{array}$ & $\begin{array}{l}- \\
- \\
-\end{array}$ \\
\hline Ether & $\cdots$ & $\cdots$ & $\cdots$ & $\cdots$ & $\cdots$ & . & $\begin{array}{c}\text { Brown syrup } \\
2 \cdot 8\end{array}$ & $\begin{array}{l}\text { E-I } \\
\text { E-2 } \\
\text { E-3 } \\
\text { E-4 } \\
\text { also I, II, III and IV }\end{array}$ & $\begin{array}{l}0 / 4 \\
0 / 4 \\
3 / 5 \\
2 / 5\end{array}$ & $\begin{array}{l}- \\
\overline{2} / 8 \\
1 / 8\end{array}$ \\
\hline Acetone & . & $\cdots$ & $\cdots$ & $\cdots$ & -. & . & $\begin{array}{c}\text { Brown syrup } \\
\text { II } 9\end{array}$ & $\begin{array}{l}\text { A-I } \\
\text { A-2 } \\
\text { also I, II, III and IV }\end{array}$ & $\begin{array}{l}0 / 5 \\
2 / 6\end{array}$ & $\overline{2 / 8}$ \\
\hline Methanol & . & $\cdots$ & -. & $\cdots$ & . & . & $\begin{array}{c}\text { Black glass } \\
4.4\end{array}$ & $\mathbf{M}$ & $2 / 5$ & - \\
\hline Fully extra & acted & .. & . & . & . & .. & Dust & & $0 / 5$ & - \\
\hline
\end{tabular}

All reactions other than I and II were weak reactions. 
TABLE V

Results of Patch Tests with Dalbergiones

\begin{tabular}{|c|c|c|c|c|c|c|c|c|c|c|c|}
\hline \multirow{2}{*}{ Test Compound } & \multirow{2}{*}{$\begin{array}{l}\text { g./IOO ml. } \\
\text { M.E.K. }\end{array}$} & \multicolumn{10}{|c|}{ Patient } \\
\hline & & $I$ & 2 & 3 & 4 & 5 & 6 & 7 & 8 & 9 & 10 \\
\hline $\begin{array}{l}\text { (R)-3, 4-Dimethoxy- } \\
\text { dalbergione }\end{array}$ & $\begin{array}{l}I \cdot 0 \\
0 \cdot I\end{array}$ & $\begin{array}{l}+++ \\
+++\end{array}$ & $\begin{array}{l}+t+ \\
++t\end{array}$ & $\begin{array}{l}+++ \\
+++\end{array}$ & $\begin{array}{l}+++ \\
++\end{array}$ & $\begin{array}{l}+++ \\
+++\end{array}$ & ++ & +++ & $+t+$ & $\begin{array}{l}+t+ \\
++t\end{array}$ & $+t+$ \\
\hline $\begin{array}{l}\text { (R)-4-Methoxy- } \\
\text { dalbergione }\end{array}$ & $\begin{array}{l}\mathbf{I} \cdot 0 \\
0 \cdot I\end{array}$ & +++ & ++ & $+t+$ & + & ++ & + & + & $+t+$ & $\begin{array}{l}++ \\
+\end{array}$ & $\begin{array}{l}++ \\
-\end{array}$ \\
\hline $\begin{array}{l}\text { (S)-4-Methoxy- } \\
\text { dalbergione }\end{array}$ & $\begin{array}{l}1 \cdot 0 \\
0 \cdot 1\end{array}$ & ++ & + & ++ & + & - & + & + & $+t+$ & $\begin{array}{l}+ \\
+\end{array}$ & - \\
\hline
\end{tabular}

Key to readings as for Table III.

Patients 9 and ro were the controls who gave strong positive reactions only at 2-3 weeks.

pared in a series of tests summarized in Table V. These compounds were applied as $0 \cdot 1$ and $I \cdot 0 \%$ solutions but, as initial reactions were severe at the higher concentration, only $0.1 \%$ was applied in subsequent tests. In general, the reactions to the (R)-3, 4-dimethoxydalbergione were more severe than those to the (R)-4-methoxydalbergione, which in turn tended to be more marked than those produced by the (S)-form.

Two control patients ${ }^{1}$ with wood dermatitis of another type gave negative reactions to the Machaerium quinone at 48 and 96 hours but 1o to 14 days later produced strongly positive reactions to this compound. This suggested a strong capacity for sensitization and no further control patients were tested with this agent.

\section{Discussion}

The sensitizing action of the wood Machaerium scleroxylon is clearly established from the above test results, and the quinone (R)-3, 4-dimethoxydalbergione and its related quinol are the sole sensitizing constituents. These compounds form $17 \%$ and $61 \%$ respectively of the petrol extract, which means that the sample of wood examined contains at least $I \cdot 0 \%$ of the quinone and $3.5 \%$ of the quinol. The lipid solubility of these compounds and their natural abundance in the wood is in accordance with the strongly sensitizing action observed for the wood dust.

M. scleroxylon is used as a substitute for D. nigra in Brazil, where both timbers occur naturally. A report to the 5 th World Forestry Congress (de Miranda Bastos and de Matos Filho, I960) indicates that trouble has also been encountered there with dermatitis accompanying its use. In the

${ }^{1}$ One of these patients was shown at the combined meeting of the Sections of Dermatology and Occupational Medicine at the Royal Society of Medicine on April 21, 1966.
United Kingdom its use as a substitute for genuine Rio rosewood appears to be a recent innovation, possibly encouraged by the recent trade demand for rosewood furniture. The sensitizing constituents I and II are closely related chemically to the dalbergione constituents of Rio rosewood (D. nigra) and cocobolo (D. retusa) (see Table I) which Schulz and Dietrichs (1962) have shown to be active in patients allergic to these two woods. In the present investigation, however, the patients sensitive to $M$. scleroxylon displayed weaker reactions to (R)-4-methoxydalbergione (one of the true rosewood constituents) and they have been able to return to work on Rio rosewood without further trouble.

The difficulties encountered in testing patients with wood extractives should not be under-rated. It is essential to obtain the full co-operation of the men and their employers and to explain the purpose and probable consequences of patch testing. When sensitivity to the wood concerned has threatened the occupation of the men themselves it is important that the pattern of reaction and, in particular, of cross-sensitization, should be explored so that they can carry out their work safely in future. But the danger of causing sensitization with these powerful quinones is apparent. Strengths used must be the weakest compatible with a positive reaction in three quarters of known affected workers; weak reactions showing negative results at this strength must be accepted on their clinical signs.

In serial testing of extractives it is wise to proceed slowly if unknown strengths are involved, but the patience of the management and men alike are sorely tested by such an approach. We should like to conclude by thanking those concerned with these outbreaks for their patience and unfailing cooperation in this work. 


\section{REFERENCES}

Eyton, W. B., Ollis, W. D., Fineberg, M., Gottlieb, O. R., Guimaraes, I, S de S., and Magalhaes, M. T. (1966a). The neoflavanoid group of natural products-II. The examination of Machaerium scleroxylon and some biogenetic proposals regarding the neoflavanoids. Tetrahedron, 21, 2697-2705.

-, - Sutherland, L. O., Gottlieb, O. R., Magalhaes, M. T., and Jackman, L. M. (1966b). The neoflavanoid group of natural products-I. Dalbergiones-a new class of quinones. Ibid., 21, 2683-2696.

Krogh, H. K. (1962). Contact eczema caused by true teak (Tectona grandis). An epidemiological investigation in a furniture factory. Brit. F. industr. Med., 19, 42-46.

- (1964). Contact eczema caused by true teak (Tectona grandis). A follow-up study of a previous epidemiological investigation, and a study into the sensitizing effect of various teak extracts. Ibid., 21, 65-68.

Marini Bettolo, G. B., Casinovi, C. G., and Galeffi, C. (1965). A new class of quinones: Sesquiterpenoid quinones of Mansonia altissima. Tetrahedron letters, No. 52, 4857-4864.

de Miranda Bastos, A., and de Matos Filho, A. (1960). A 'jacaranda' timber causing dermatitis. Proc. 5th Wld Forestry Congr., pp. I414-1415.

Morgan, J. W. W., and Orsler, R. J. (1967). A simple test to distinguish Khaya anthotheca from $K$. ivorensis and K. grandifoliola. F. Inst. Wood Sci., No. 18, 6I-64.

-, and Wilkinson, D. S. (1965a). Sensitization to Khaya anthotheca. Nature, 207, I IOI.
(I965b). Dermatitis produced by wood. Proc. I.U.F.R.O. Congr., Section 4I, Vol. 3.

Phillips, E. W. J. (I966). Dermatitis caused by a rosewood substitute. Wood, 31 (9), 44-45.

Sandermann, W., and Barghoorn, A. W. (1955). Utber die Inhaltsstoffe von Makoré- und Peroba-Holz sowie ihre gesundheitsschädigende Wirkung. Holzforschung, 9, II2-II7.

,-- (1956). Gesundheitsschädigende Hölzer. Holz als Roh- $u$. Werkstoff, 14, 37-40 and 87-94.

—, and Dietrichs, H. H. (1959). Chemische Studien an Tropenhölzern-3. Mitteilung: Uber die Inhaltsstoffe von Mansonia altissima und ihre gesundheitsschädigende Wirkung. Holz als Roh- $u$. Werkstoff, 17, 88-97.

- and Simatupang, M. H. (1962). A toxic quinone from teak wood. Angew. Chem. (Internat. ed.), 1, 599.

_, - (1963). Úber Inhaltsstoffe aus Teak (Tectona grandis $L$ ). I. Isolierung und Konstitution eines toxischen Teakchinons. Chem. Ber., 96, 2182-2185.

Schulz, K. H. (1957). Allergische Kontaktdermatitis durch exotische Hölzer, insbesondere durch KambalaTeakholz. Berufsdermatosen, 5, 238-244.

- (1962). Untersuchungen über die sensibilisierende Wirkung von inhaltsstoffen exotischer Hölzer. Ibid., I0, 1 7-27.

- , and Dietrichs, H. H. (1962). Chinone als sensibilisierende Bestandteile von Rio- Palisander- (Dalbergia nigra) und Cocobolo- (Dalbergia retusa) Holz. Allergie u. Asthma, 8, 125-131. 